RUNNING HEAD: TRUE \& FABRICATED MEMORIES

\title{
True and Intentionally Fabricated Memories
}

\author{
Lucy V. Justice ${ }^{1}$, Catriona M. Morrison ${ }^{2}$, \& Martin A. Conway ${ }^{3}$ \\ 1,2 Institute of Psychological Sciences, University of Leeds, Leeds, England \\ ${ }^{3}$ Department of Psychology, City University, London, England
}

Address for correspondence:

Professor Martin A. Conway

Department of Psychology

City University,

Northampton Square,

London, EC1V 0HB

Email: martinconway1@me.com 


\begin{abstract}
The aim of the experiment reported here was to investigate the processes underlying the construction of truthful and deliberately fabricated memories. Properties of memories created to be intentionally false - fabricated memories - were compared to properties of memories believed to be true - true memories. Participants recalled and then wrote or spoke true memories and fabricated memories of everyday events. It was found that true memories were reliably more vivid than fabricated memories and were nearly always recalled from a first person perspective. In contrast, fabricated differed from true memories in that they were judged to be reliably older, were more frequently recalled from a third person perspective, and linguistic analysis revealed that they required more cognitive effort to generate. No notable differences were found across modality of reporting. Finally, it was found that, intentionally fabricated memories were created by recalling and then 'editing' true memories. Overall, these findings show that true and fabricated memories systematically differ, despite the fact that both are based on true memories.
\end{abstract}


One of the functions of memory is in imagining. Imagining, for example, how the future might be or how the past might have been otherwise. Indeed, memory and imagining are so interconnected it has been suggested that together they form a remembering-imagining system (Conway, 2009). Although much research has focused on the association between imagining the future and autobiographical memory (Addis, Wong, \& Schacter, 2007; D’Argembeau \& Van der Linden, 2004; Hassabis, Kumaran, \& Maguire, 2007; Hassabis, Kumaran, Vann, \& Maguire, 2007; Newby-Clark \& Ross, 2003; Schacter \& Addis, 2009; Schacter, Addis, \& Buckner, 2008; Szpunar \& McDermott, 2008; Tulving, 1985; Tulving, 2002), little research has investigated our ability to imagine an alternative past. Therefore, in the present study we directly compare intentionally fabricated autobiographical memories (IFAMs) with autobiographical memories (AMs) the rememberer believes to be true and which they experience as memories. An IFAM is an entirely or partially fabricated memory, consisting primarily, but not exclusively of false facts, as opposed to the expression of false opinions or beliefs (see Newman et al., 2003, for differences in false opinions). IFAMs may arise in forensic contexts, and become particularly pivotal in instances when memory is the only form of evidence available. The sorts of cases in which memories are the only evidence include, what in the UK are termed, cases of 'historic' sexual abuse (typically memories dating to childhood recalled by an adult complainant), accident assessments, war, torture, political asylum, and plagiarism. Moreover, reports of fabricated memories are a common feature of forensic interviews and interrogations (Porter \& Yuille, 1996, Porter, Yuille and Lehman, 1999) and a number of reasons and motivations for deliberately fabricating memories may exist including revenge, control and monetary gain (Yuille, Tymofievich, \& Marxsen, 1995). 
However, a small body of work has begun investigating IFAMs, with particular focus falling on systematic differences between real and fabricated memories (Conway, Pleydell-Pearce, Whitecross, \& Sharpe, 2003; Merckelbach, 2004; Porter, Peace, \& Emmett, 2007; Porter, Yuille, \& Lehman, 1999), Although little empirical work has investigated the construction processes of IFAMs, it has been suggested that an IFAM is created by means of a 'lie script' . According to this view, a generic representation of an event is generated and is then used in place of a specific memory of a single event. A process that has been termed 'superficial encoding' (Porter \& Yuille, 1996). This theory has had some support, (Granhag \& Strömwall, 1999, Granhag, Strömwall, \& Jonsson, 2003) and has led to the view that truth tellers create their accounts through reconstruction, whereas liars attempt to accurately repeat a previously rehearsed script. According to these theories, it is these differences in processing and storage that are responsible for systematic and measureable differences in in truthful and fabricated memory accounts (Colwell, HiscockAnisman, Memon, Taylor, \& Prewett, 2007).

Porter (1998) further suggests that verbal ideas and images may play a role in IFAM generation, arguing that fabricated memories are "imaginative constructions". However, Porter (1999), later, proposed that fabricated memories may not be entirely imaginative in nature, but like false memories (untrue memories that, unlike fabricated memories are not known to be false), may incorporate elements of an experienced event with the purpose of enhancing the credibility of an account. In a rather similar and related way it has been suggested that the process of lying involves firstly accessing true beliefs followed by denial and/or distortion of these beliefs (Polage, 2004). Despite this work, to our knowledge, no empirical research has 
explicitly addressed the construction processes involved in IFAM construction (with the exception of Conway, et al., 2003). Therefore, the primary aim of the present research is to understand the way in which IFAMs are constructed within the autobiographical memory system. By understanding such processes, we can better understand how IFAMs are stored, rehearsed and recalled, and why differences may occur in their content.

The generation or construction of AMs involves the effortful, iterative, access of autobiographical memory knowledge structures and the gradual establishment of patterns of activation/inhibition across distributed neural networks that come to form an AM in an act of remembering (Cabeza \& Jacques 2007; Conway, et al., 2003, 2005; Conway \& Pleydell-Pearce, 2000). It seems that the construction of IFAMs may involve similar processes, not least because the generation of IFAMs may feature the recall of AMs. It is difficult to conceive of a process of IFAM generation that did not feature, to a least some extent, access of autobiographical knowledge and possibly the generation of specific AMs. The present research is consistent with this and follows from the assumption that IFAM creation involves initially accessing information in long-term memory, followed by a conscious "editing" phase. In other words, an AM is activated and then consciously edited to produce an IFAM.

Some evidence supporting this assumption comes from an EEG study by Conway, et al., (2003) contrasting the construction and retention of IFAMs and AMs. In the construction phase no differences in activation were found between IFAMs and AMs and the patterns of activation were highly similar to those observed in a prior 
study of AM generation (Conway, Pleydell-Pearce, \& Whitecross, 2001) . However, in a retention phase during which IFAMs and AMs were held in mind for 10s a major difference did emerge and that was increased right frontal activation during IFAM retention. This may have reflected the editing of AMs and subsequent difficulties in consciously maintaining the novel IFAM representation.

Because of the editing process, and effort required to maintain a novel representation, IFAMs should differ from AMs in some of their recollective qualities. For example, memories not based on real experience may be associated with less vivid mental imagery (Johnson \& Raye, 1981), may be placed further back in the past to demonstrate a stable, long-held memory and may be recalled more frequently through an observer perspective, since an observer perspective has been shown to occur following distortion (Freud, 1915; Nigro \& Neisser, 1983). Further, AMs may require less cognitive effort to generate (Vrij, et al., 2008) and may also be faster to create. We, therefore, expect to find linguistic constructs within accounts of IFAMs that are indicators of cognitive effort, for example fewer complex words e.g. those over six letters in length and a higher rate of non-fluencies, e.g. "erm", "umm", particularly for spoken accounts). Further, we expect that IFAMs will contain more motion words, e.g. walk, go, run. Motion words have been found to be a characteristic of increased cognitive effort, used by a rememberer to reduce the complexity of an account by referring to simple actions rather than expression of emotions or other metacognitive reasoning (Newman, Pennebaker, Berry, \& Richards, 2003). Finally, IFAMs may be shorter in length than AMs to avoid unnecessary discussion of detail. 
Additional linguistic differences such as an increase in negative emotion words, fewer exclusive and sensation words in IFAMs have been shown by Newman et al. (2003), however we did not expect to find these linguistic differences since our study was investigating fabricated memories rather than fabricated opinions and denials (Newman, et al. , 2003). In summary then, four recollective qualities, vividness, memory / image generation times, retention interval, and perspective and four linguistic constructs, complex words, non-fluencies, motion words and account length, all assumed to reflect cognitive effort and / or an editing process, were investigated. Accounts of the memories were recorded by either typing or by tape recording while they were spoken ${ }^{1}$.

\section{Method}

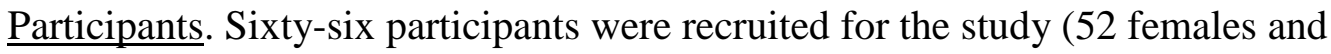
14 males). Their ages ranged from 18 - 57 years, with a mean age of 21 . Forty-eight participants took part in the study for course credits as part of their undergraduate studies at The University of Leeds, and the remaining 18 participants received small payment.

Figure 1 about here

Materials and Procedure. Error! Reference source not found. shows the presentation order of cues and ratings for each trial of the study. Participants were tested individually and all testing was completed using a computer. Participants were presented with a computer screen displaying "RECALL" or "IMAGINE.". Following

\footnotetext{
${ }^{1}$ Differences were not expected between the two modalities but as witnesses usually speak their memories aloud it was thought that the two modalities should be contrasted.
} 
this a cue was displayed, e.g. going to a restaurant. There were 20 cues naming common everyday activities, (taken from Bower, Black, \& Turner, 1979; Trafimow \& Wyer, 1993; Reiser, Black, \& Abelson, 1985). Cues were counterbalanced across participants and conditions, ensuring that all cues were used to generate both IFAMs and AMs. One block of 10 cues instructed the participant to recall, the other, imagine. There was a short 2-mimute pause between blocks while the instructions for the next block, which notified the participant of the final condition (AM or IFAM), were reviewed. Participants were instructed to generate either a truthful memory or imagine an event that had never occurred associated with the given cue. They were then instructed to press the space bar once they had brought clearly to mind a memory or imagined a fabricated past event, there was no upper or lower time limit on memory retrieval / image generation. Participants were instructed to ensure that they imagined all fabricated events being in the past and to describe them as if they were trying to convince another person that the event had actually been experienced. For AMs they were instructed to bring to mind a memory of an event which they had directly experienced that had lasted for minutes or hours but no longer than one day. Both types of memory could be recalled or located at any point in their own personal past, they were not limited to specific time periods. Participants were instructed to construct memories as quickly as they could but to ensure they were specific.

Memory retrieval and image generation times were recorded in milliseconds from cue on-screen to space bar press. Participants were randomly assigned to conditions and half typed a description of the memory into the computer and the other half spoke their memory into a Dictaphone. After a memory had been provided, participants rated the vividness of AMs and IFAMs using 7-point scales (1=low, 
7=high). Participants also indicated the perspective or point-of-view in their memory: they were instructed to judge a memory as having an 'observer' perspective if they saw themselves in the memory and to judge a 'field' perspective if they had something approximating to their original perspective or what would have been their original perspective for an IFAM. Finally, participants were asked to judge the approximate age at which the memory had occurred. They were instructed to plausibly fabricate this for IFAMs. Lastly participants took part in short postexperimental interviews in which they were asked how they had created their IFAMs.

\section{Results}

Table 1 about here

Recollective Qualities. 2 × 2 mixed model ANOVAs, with two levels of memory reporting (typed vs spoken) and two memory types (AM vs IFAM) were conducted for three separate recollective qualities (vividness, memory retrieval / image generation time and retention interval). A main effect of memory type was found for vividness, $\mathrm{F}(1,64)=27.2, \mathrm{MSe}=0.6, \mathrm{p}<0.001, \eta 2=0.3$ and retention interval, $\mathrm{F}(1$, $64)=16.6, \mathrm{MSe}=2.1, \mathrm{p}<0.001, \eta 2=0.2$, indicating that AMs were reliably more vivid and had a reliably shorter retention interval, i.e. were more recent than IFAMs.. Additionally, although IFAMs were found to take longer to generate than AMs, this difference was not reliable, most likely due to the large amount of variation in memory / image generation times. Error! Reference source not found. shows the means and standard deviations (in parentheses). To investigate the relationship between vividness and retention interval, separate correlation analyses of these variables were conducted. Results showed that for AMs, age was reliably positively 
correlated with vividness $(\mathrm{r}=0.35, \mathrm{p}<0.001)$, such the more recent the memory the more vivid it was. No other reliable differences or correlations were found.

Table 2 here

Memory perspective was investigated using Chi-Square. It was found that $76 \%$ of AMs had a field perspective (the participant sees the memory through their own eyes) and the remaining $24 \%$ had an observer perspective (the participant sees themselves in the memory). For IFAMs $48 \%$ of imagined events had an observer perspective with $52 \%$ a field perspective. These differences in perspective between AMs and IFAMs were found to be reliable overall, $\left(X^{2}(1)=94.4, p<0.001\right)$.

Content Analysis. Memory accounts were analysed for four predefined linguistic constructs: motion words, complex words, non-fluencies and account length for both AMs and IFAMs. The counts were made using the Linguistic Inquiry and Word Count, LIWC, program (Pennebaker, Francis, \& Booth, 2001) and the totals for each memory in each of the IFAM and AM conditions were entered into separate 2 (memory reporting) x 2 (memory type) ANOVAs. A main effect of memory type was found for motion words $(\mathrm{F}(1,63)=10.7, \mathrm{MSe}=0.6, \mathrm{p}<0.005, \eta 2=0.1)$ and an interaction effect was found for non-fluencies $(\mathrm{F}(1,64)=15.0, \mathrm{MSe}=1.1, \mathrm{p}<0.001$, $\eta 2=0.2$ ). The means (see Table 1) indicated that accounts of IFAMs featured reliably more motion words than AMs and reliably more non-fluencies than AMs but only when the memory was spoken. No other reliable differences were found.

Finally, in the post-experimental interview, when asked how they had generated the fabricated memories, all participants stated that they had created their IFAMs either by recalling specific memories and editing them, or by recalling an 
item of autobiographical knowledge and constructing a fabricated memory around it. Both strategies were common and most participants used both.

\section{$\underline{\text { General Discussion }}$}

The present findings (Tables 1 and 2) show that IFAMs and AMs differ in important ways despite the fact that IFAMs are based on AMs or other autobiographical knowledge. Autobiographical memories were found to be more vivid and to date to more recent times than IFAMs. Importantly for AMs, but not for IFAMs rated vividness correlated with the recency of a memory and more recent AMs were judged more vivid. These differences and relations may reflect beliefs about memory (see Justice, Morrison, \& Conway, 2012, for recent work on beliefs about memory). For example, a person might believe that the older a memory the more likely it is to be believed to be true. Possibly this is because it makes an IFAM appear more embedded in a person's autobiographical memory. Or, perhaps, there is a belief too that an older memory has had more opportunities to be scrutinised and contradicted and so in a way its truth has been tested. Similarly, it may be the case that participants either implicitly or intentionally believe that claiming a memory is from further in the past makes it less likely that others will remember it themselves and/or search for verification. These beliefs may have led our participants to reliably date their IFAMs to more remote dates than their AMs. Interestingly, the correlation between vividness and recency of memory is probably not one that the general population is aware of and therefore it does not influence judgments of age of memory and vividness for IFAMs as it does for true autobiographical memories. 
IFAMs were also found to take longer to generate than AMs. Although this finding was not reliable, due to large variations in the data, it may nonetheless reflect additional processes occurring in IFAM generation, and that is, we suggest, a process of conscious 'editing', as the participants indicated in their post-experimental interviews.

Undoubtedly one of the most important findings of the present study, shown in Table 2, are the differences in memory perspective between AMs and IFAMs. Here, AMs were strongly associated with a field perspective and this is surely what would be expected for memories of directly experienced events. The dominance of the field perspective in AMs only seems to diminish for negative emotional experiences (Freud, 1915; Nigro \& Neisser, 1983) and when memory is incompatible with some aspect of the self (Libby, Eibach, \& Gilovich, 2005). In these cases the observer perspective increases. For our participants, generating IFAMs that were intended to convince others that they were true, may have been rather similar to lying and that in itself may have been sufficient for them to distance themselves in their IFAMs and do so by taking an observer perspective. Whatever the case, the findings suggest that fabricated autobiographical memories are just as likely to have a field or observer perspective, whereas this is not the case for true autobiographical memories. As Freud (1915) originally noted, an observer perspective indicated a 'memory' that has been further processed or 'edited' after formation and that may then indicate, on at least some occasions, a fabricated memory. 
Finally, it was observed that accounts of IFAMs contained more motion words and more non-fluencies. The increases in motion words and non-fluencies are considered to reflect increasing cognitive effort within an account or statement (Newman et al., 2003).We suggest this occurs for IFAMs relative to AMs in part because of the editing process and in part because holding a novel mental representation while describing it may be more cognitively effortful than describing a more permanent long-term memory representation. As regards the 'editing' process, although we did not formally test this, responses from the post-experimental interview indicated that this often took the form of 'deletion-substitution'. For instance, the memory "Going the new Italian restaurant with $\mathrm{X}, \mathrm{Y}$, and $\mathrm{Z}$, last Saturday" might be edited to "Going the usual restaurant with X,Y, and Z, last Saturday". Clearly, such a process is in addition to retrieving the memory and therefore is more complex and effortful. Similarly, holding in mind, say, a visual image of an IFAM may require constant refreshing of the image to maintain the changed or substituted detail (Kossyln, 1983). Again making IFAM construction more effortful, increased effort that is subsequently reflected in the verbal account of the memory.

Taken together, then, data from both recollective qualities and linguistics suggests a process of IFAM generation that is more effortful than AM generation. IFAMS are less vivid and less recent, and do not show a systematic relationship between vividness and age of memory. Most strikingly, however, intentionally fabricated memories are less likely than true AMs to have a field perspective and more likely to have an observer perspective. Further, they contain language that is representative of a reduction in cognitive complexity, such as an increase in the use 
of motion words and an increase in the number of (spoken) non-fluencies. These differences in characteristics of the two types of memories and in their verbal description reflect the differing cognitive processes underlying IFAM and AM generation, strengthening the argument that IFAMs are more effortful to generate due to an additional process of 'editing'.

The present experiment is the first to investigate the processes by which IFAMs are generated. Understanding these processes is integral to future work investigating IFAMs and lying more generally. Understanding the editing phase more fully i.e. deletion-substitution and other forms of editing, may lead to new ways to identify intentionally false autobiographical memories. It may also eventually indicate ways in which IFAMs become integrated with autobiographical memory over time, and, perhaps, with repeated rehearsal become indistinguishable from true autobiographical memories. 


\section{$\underline{\text { References }}$}

Addis, D. R., Wong, A. T., \& Schacter, D. L. (2007). Remembering the past and imagining the future: common and distinct neural substrates during event construction and elaboration. Neuropsychologia, 45(7), 1363-1377.

Bower, G. H., Black, J. B., \& Turner, T. J. (1979). Scripts in memory for text. Cognitive Psychology, 11(2), 177-220.

Cabeza, R., \& Jacques, P. S. (2007). Functional neuroimaging of autobiographical memory. Trends in Cognitive Sciences, 11(5), 219-227.

Colwell, K., Hiscock-Anisman, C. K., Memon, A., Taylor, L., \& Prewett, J. (2007). Assessment criteria indicative of deception ( ACID ): an integrated system of investigative interviewing and detecting deception. Journal of Investigative Psychology and Offender Profiling, 180(3), 167-180.

Conway, M. A., (2009). Episodic memories. Neuropsychologia, 47(11), 2305-2313.

Conway, M. A. \& Pleydell-Pearce, C. W. (2000). The construction of autobiographical memories in the Self-Memory System. Psychological Review, 107(2), 261-288.

Conway, M. A., Pleydell-Pearce, C. W., Whitecross, S. E., \& Sharpe, H. (2003). Neurophysiological correlates of memory for experienced and imagined events. Neuropsychologia, 41(3), 334-340.

Conway, M A, Pleydell-Pearce, C. W. \& Whitecross, S. E. (2001). The neuroanatomy of autobiographical memory: a slow cortical potential study of autobiographical memory retrieval. Journal of Memory and Language, 45(3), 493-524.

D’Argembeau, A., \& Van der Linden, M. (2004). Phenomenal characteristics associated with projecting oneself back into the past and forward into the future: influence of valence and temporal distance. Consciousness and Cognition, 13(4), 844-58. 
Freud, S. (1915). Repression. In J. Strachey (Ed.). The standard edition of the complete works of Sigmund Freud, Vol. 14, pp. 146-158. London: Hogarth Press.

Granhag, P. A., \& Strömwall, L. A. (1999). Repeated interrogations - stretching the deception detection paradigm. Expert Evidence, 7(3), 163-174.

Granhag, P. A., Strömwall, L. A., \& Jonsson, L. A. (2003). Partners in crime: how liars in collusion betray themselves. Journal of Applied Social Psychology, 33(4), 848-868.

Hassabis, D., Kumaran, D., \& Maguire, E. A. (2007). Using imagination to understand the neural basis of episodic memory. Journal of Neuroscience, 27(52), 14365-14374.

Hassabis, D., Kumaran, D., Vann, S. D., \& Maguire, E. A. (2007). Patients with hippocampal amnesia cannot imagine new experiences. Proceedings of The National Academy of Sciences of the United States of America, 104(5), 1726-1731.

Johnson, M. K., \& Raye, C. L. (1981). Reality monitoring. Psychological Review, 88(1), 6785.

Justice, L. V., Morrison, C. M., \& Conway, M. A. (2012). Beliefs about autobiographical memory. Under review.

Kosslyn, Stephen M. (1983). Ghosts in the mind's machine: creating and using images in the brain. New York: Norton.

Libby, L. K., Eibach, R. P., \& Gilovich, T. (2005). Here's looking at me: the effect of memory perspective on assessments of personal change. Journal of Personality and Social Psychology, 88(1), 50-62.

Merckelbach, H. (2004). Telling a good story: fantasy proneness and the quality of fabricated memories. Personality and Individual Differences, 37(7), 1371-1382. 
Nigro, G. \& Neisser, U. (1983). Point of view in personal memories. Cognitive Psychology, 15(4), 467-482.

Newby-Clark, I. R., \& Ross, M. (2003). Conceiving the Past and Future. Personality and Social Psychology Bulletin, 29(7), 807-818.

Newman, M. L., Pennebaker, J. W., Berry, D. S., \& Richards, J. M. (2003). Lying words: predicting deception from linguistic styles. Personality and Social Psychology Bulletin, 29(5), 665-675.

Nigro, G., \& Neisser, U. (1983). Point of view in personal memories. Cognitive Psychology, 15(4), 467-482.

Pennebaker, J.W., Booth, R.J., \& Francis, M.E. (2007). Linguistic Inquiry and Word Count: LIWC 2007. Austin, TX.

Polage, D. C. (2004). Fabrication deflation? The mixed effects of lying on memory. Applied Cognitive Psychology, 18(4), 455-465.

Porter, S. (1998). An architectural mind: the nature of real, created, and fabricated memories for emotional childhood events. Doctoral dissertation, University of British Columbia, Vancouver, British Columbia, Canada.

Porter, S., Peace, K. A., \& Emmett, K. A. (2007). You protest too much, methinks: investigating the features of truthful and fabricated reports of traumatic experiences. Canadian Journal of Behavioral Science, 39(2), 79-91.

Porter, S., Yuille, J. C., \& Lehman, D. R. (1999). The nature of real, implanted, and fabricated memories for emotional childhood events: implications for the recovered memory debate. Law and Human Behavior, 23(5), 517-537. 
Reiser, B. J., Black, J. B., \& Abelson, R. P. (1985). Knowledge structures in the organization and retrieval of autobiographical memories. Cognitive Psychology, 17(1), 89-137.

Schacter, D. L., \& Addis, D. R. (2009). Remembering the past to imagine the future: a cognitive neuroscience perspective. Military Psychology, 21, S108-S112.

Schacter, D. L., Addis, D. R., \& Buckner, R. L. (2008). Episodic simulation of future events: concepts, data, and applications. Annals of the New York Academy of Sciences, Special Issue: The Year in Cognitive Neuroscience, 1124, 39-60.

Szpunar, K. K., \& McDermott, K. B. (2008). Episodic future thought and its relation to remembering: evidence from ratings of subjective experience. Consciousness and Cognition, 17(1), 330-334.

Trafimow, D., \& Wyer, R.S., Jr. (1993). Cognitive representation of mundane social events. Journal of Personality and Social Psychology, 64, 365-376.

Tulving, E. (1985). Memory and consciousness. Canadian Psychology-Psychologie Canadienne, 26(1), 1-12.

Tulving, E. (2002). Chronesthesia: Awareness of subjective time. In D. T. Stuss \& R. C. Knight (Eds.), Principles of frontal lobe function, pp. 311-325, New York: Oxford University Press.

Vrij, A., Mann, S. A, Fisher, R. P., Leal, S., Milne, R., \& Bull, R. (2008). Increasing cognitive load to facilitate lie detection: the benefit of recalling an event in reverse order. Law and Human Behavior, 32(3), 253-265.

Yuille, J. C., Tymofievich, M., \& Marxsen, D. (1995). The nature of allegations of child sexual abuse, in T. Ney (Ed.) Allegations of child sexual abuse: assessment and case management (pp. 21-46). Philadelphia: Brunner/Mazel. 


\section{$\underline{\text { Authors Note }}$}

Martin Conway was supported by an Economic and Social Research Council project grant, RES-189-25-0226, and Lucy Justice by a University of Leeds, Institute of Psychological Sciences postgraduate grant. Both authors thank the respective institutions for their support. Electronic mail correspondence can be directed to the Martin Conway at: Martin.Conway.1@ @ity.ac.uk 